\title{
Prevalence of unintended pregnancy and needs for family planning among married adolescent girls living in urban slums of Dhaka, Bangladesh
}

Fauzia Akhter Huda

Sabiha Chowdhuri

Bidhan Krishna Sarker

Noushin Islam

Anisuddin Ahmed

Follow this and additional works at: https://knowledgecommons.popcouncil.org/departments_sbsr-rh

Part of the Demography, Population, and Ecology Commons, Family, Life Course, and Society Commons, Inequality and Stratification Commons, International Public Health Commons, Maternal and Child Health Commons, and the Women's Health Commons How does access to this work benefit you? Let us know!

\section{Recommended Citation}

Akhter Huda, Fauzia, Sabiha Chowdhuri, Bidhan Krishna Sarker, Noushin Islam, and Anisuddin Ahmed. 2014. "Prevalence of unintended pregnancy and needs for family planning among married adolescent girls living in urban slums of Dhaka, Bangladesh," STEP UP Research Report. Dhaka: icddr,b. 


\section{STEPTUP}

STRENGTHENING EVIDENCE FOR PROGRAMMING ON UNINTENDED
PREGNANCY

BANGLADESH

RESEARCH REPORT

JUNE 2014

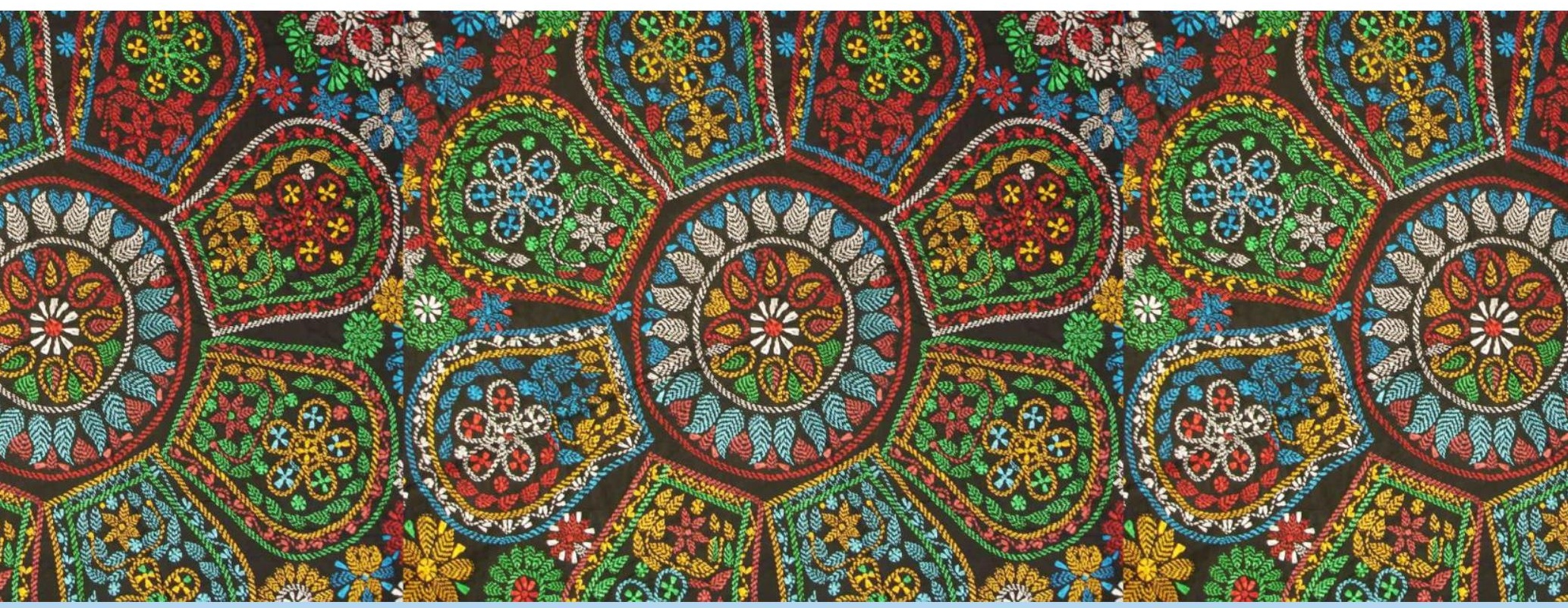

\section{Prevalence of unintended pregnancy and needs for family planning among married adolescent girls living in urban slums of Dhaka, Bangladesh}

FAUZIA AKHTER HUDA, SABIHA CHOWDHURI, BIDHAN KRISHNA SARKER, NOUSHIN ISLAM AND ANISUDDIN AHMED 


\section{Prevalence of unintended}

pregnancy and needs for family planning among married adolescent girls living in urban slums of Dhaka, Bangladesh

FAUZIA AKHTER HUDA, SABIHA CHOWDHURI, BIDHAN KRISHNA SARKER, NOUSHIN ISLAM, ANISUDDIN AHMED

Centre for Reproductive Health, icddr,b, Dhaka, Bangladesh 
The STEP UP (Strengthening Evidence for Programming on Unintended Pregnancy) Research Programme Consortium generates policy-relevant research to promote an evidence-based approach for improving access to family planning and safe abortion. STEP UP focuses its activities in five countries: Bangladesh, Ghana, India, Kenya and Senegal. STEP UP is coordinated by the Population Council in partnership with the African Population and Health Research Center; icddr,b; the London School of Hygiene and Tropical Medicine; Marie Stopes International and Partners in Population and Development. STEP UP is funded by UKaid from the UK Government. www.stepup.popcouncil.org

\section{(0) icddr,b}

Dedicated to saving lives, icddr,b is an international public health research organisation located in Bangladesh. Through the generation of knowledge and translation of research into treatment, training, and policy advocacy, icddr,b addresses some of the most critical health concerns facing the world today. www.icddrb.org

\section{POPULATION 7 COUNCIL \\ Ideas. Evidence. Impact.}

The Population Council confronts critical health and development issues-from stopping the spread of HIV to improving reproductive health and ensuring that young people lead full and productive lives. Through biomedical, social science and public health research in 50 countries, we work with our partners to deliver solutions that lead to more effective policies, programs and technologies that improve lives around the world. Established in 1952 and headquartered in New York, the Council is a nongovernmental, nonprofit organization governed by an international board of trustees. www.popcouncil.org

Suggested citation: Huda, FA; Chowdhuri, S; Sarker, BK; Islam, N and Ahmed A. 2014. "Prevalence of unintended pregnancy and needs for family planning among married adolescents girls living in urban slums of Dhaka, Bangladesh" STEP UP Research Report. Dhaka: icddr,b.

(c) 2014 icddr,b.

Please address any inquiries about STEP UP to the RPC co-directors:

Dr. Harriet Birungi, hbirungi@popcouncil.org

Dr. lan Askew, laskew@popcouncil.org

Funded by

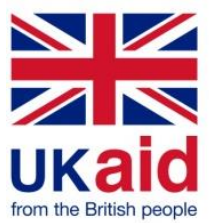




\section{Table of Contents}

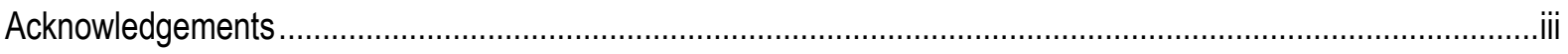

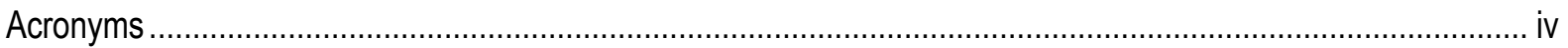

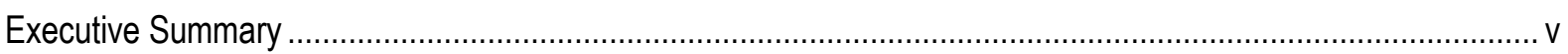

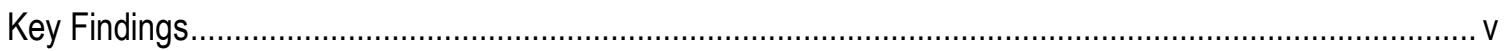

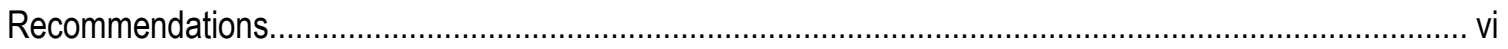

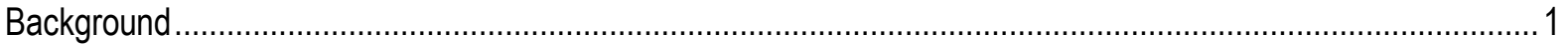

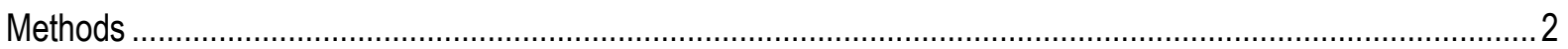

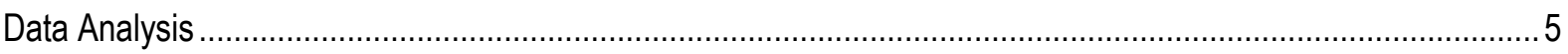

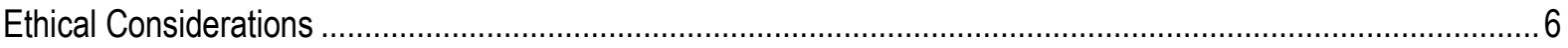

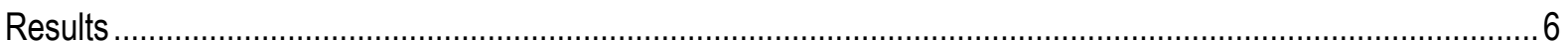

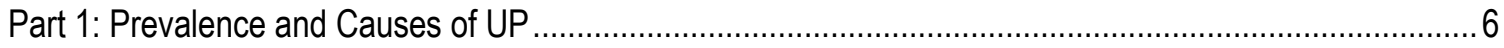

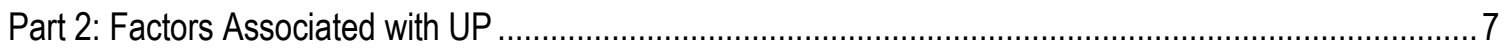

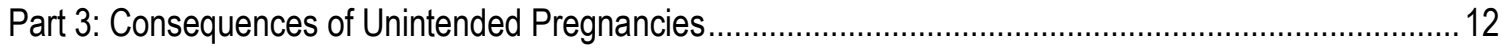

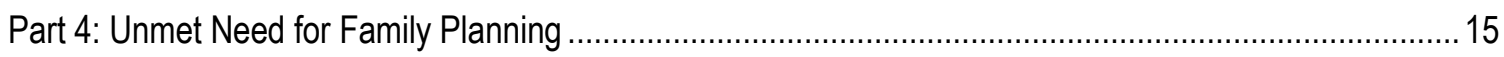

Part 5: Barriers to Access and Effective Use of FP and MR Services ................................................... 17

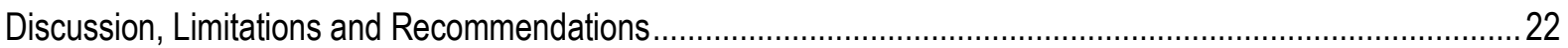

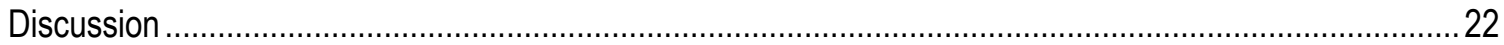

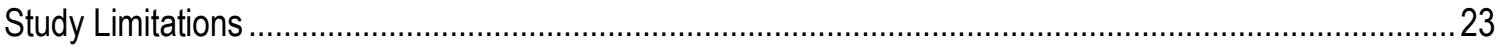

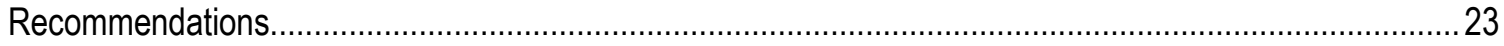

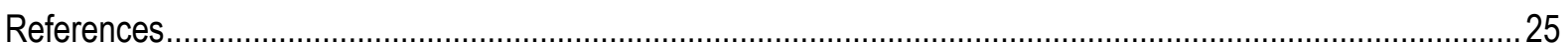




\section{List of Tables and Figures}

\section{Tables}

Table 1: Percent distribution of married adolescent girls by background characteristics

Table 2: Percent distribution of married adolescent girls with unintended pregnancy by socio-demographic characteristics

Table 3: Prevalence of unintended pregnancy among married adolescent girls by knowledge and perceptions about marriage, childbirth and family planning.

Table 4: Prevalence of unintended pregnancy among married adolescent girls by spousal agreement on childbearing

Table 5: Percent distribution of intended and unintended pregnancies by various health outcomes .12

Table 6: Spousal intentions and pregnancy outcomes at a glance. .13

Table 7: Percent distribution of married adolescent girls with unmet need for family planning by background characteristics

Table 8: Percent distribution of married adolescent girls with unmet need for family planning by reasons for not using a method

Table 9: Percent distribution of married adolescent girls with unmet need for family planning by indicators of support for method use

Table 10: Percent distribution of married adolescent girls who had used family planning by timing and type of method . .18

Table 11: Current Status of FP method use and Reasons for discontinuation. .18

Table 12: Percent distribution of married adolescent girls who had never used a method by reasons for non-use..

Table 13: Percent distribution of married adolescent girls by sources of information on family planning......

Table 14: Percent distribution of married adolescent girls by knowledge of source of family planning methods ..21

\section{Figures}

Figure 1: Percent distribution of respondents with UP by its major causes .....

Figure 2: Percent distribution of UP by respondent's age at conception

Figure 3: Knowledge about FP (before marriage) among respondents with unintended and intended pregnancies.

Figure 4: Knowledge about ECP (before marriage) among respondents with unintended and intended pregnancies.

Figure 5: Prevalence of UP by perceptions about responsibility for FP method use 


\section{Acknowledgements}

We acknowledge support from the STEP UP (Strengthening Evidence for Programming on Unintended Pregnancy) Research Programme Consortium. STEP UP was funded by UKaid from the Department for International Development (DFID), grant number SR1111D-6.

The authors are indebted to STEP UP partners, Population Council, Kenya, African Population and Health Research Center (APHRC) Kenya, and Population Council, Ghana, who offered their invaluable advice during the data analysis workshop in Mombasa, Kenya during February 17-21, 2014. The authors are especially grateful to Dr. Harriet Birungi, Dr. Francis Onyango and Dr. lan Askew of the Population Council, Kenya for their guidance throughout the development of this report.

The authors would also like to thank Partners in Population and Development (PPD) for their role in disseminating the preliminary findings of the report at the national level.

icddr,b is thankful to the Governments of Australia, Bangladesh, Canada, Sweden and the UK for providing core/unrestricted support. 


\section{Acronyms}

BDHS Bangladesh Demographic and Health Survey

DSF Demand Side Financing

FP Family Planning

FRA Field Research Assistant

FRS Field Research Supervisor

IDI In-Depth Interview

IEC Information, Education and Communication

MR Menstrual Regulation

NGO Non-Governmental Organization

OCP Oral Contraceptive Pill

UP Unintended Pregnancy 


\section{Executive Summary}

Early marriage and early childbearing in Bangladesh has led to an adolescent fertility rate that is among the highest in the world and are also associated with high levels of unintended pregnancy (UP). Although research exists on UP and contraceptive use among married adolescent girls in Bangladesh, studies that focus on vulnerable groups such as married adolescent girls living in urban slums is limited. This study examined the prevalence and basic underlying factors of UP among married adolescent girls in five urban slums in Dhaka, Bangladesh. The specific objectives of the study were to: (1) document the prevalence of UP among married adolescent girls aged 15-19 years living in urban slums of Dhaka, Bangladesh; (2) identify the factors associated with or which contribute to UP among urban married adolescent girls; (3) estimate the proportion of married adolescent girls who have an unmet need for family planning (FP) services; and (4) explore the barriers to access and effective use of FP and menstrual regulation (MR) services among married adolescent girls in urban slums.

The study was conducted between May through September 2013 and had two components. The first component involved a quantitative survey among 1,008 married adolescent girls aged 15-19 years in five purposively selected slum areas of Dhaka (Kamrangirchar, Shyampur, Rayerbazar, Shekhertek and Mirpur). Information was collected on the socio-demographic characteristics of the respondents, their knowledge and perceptions about FP, reproduction and pregnancy, FP practices, fertility preferences, spousal communication, ,and barriers of using FP services. The second component involved 29 in-depth interviews with a subset of married adolescent girls who reported in the survey that they had experienced UP (15 participants) and their spouses (14 participants). Analysis of the quantitative data involved cross-tabulations with chi-square tests to examine variations in UP and unmet need for FP by socio-demographic characteristics of the respondents as well as their knowledge of FP, approval of FP use, and spousal communication between them and their husbands on fertility preferences. The qualitative data were analyzed for content to identify emerging themes.

\section{Key Findings}

- High levels of unintended pregnancy among married adolescent girls in urban slums: More than half of the pregnancies (53\%) among the married adolescent girls in urban slums were unintended. The prevalence of UP was more than twice higher among married adolescent girls in the slums than among a similar group of adolescent girls in all urban or rural areas of Bangladesh $(22 \%$ and $24 \%$ of the births to married adolescent girls in these settings were unintended).

- Unintended pregnancy among married adolescent girls in the urban slums was largely due to improper use or non-use of FP arising from user-related factors: The most common reasons for unintended pregnancies were inconsistent use of FP methods especially pills, condoms and injectables, being unaware of available methods, fear of side effects, method failure, and pressure from their spouses and relatives (primarily mothers-in-law) to have children. Other factors included lack of spousal communication, uncovered gap between switching from one method to another method, and wrong calculation of the safe period. Those who experienced UP were also less likely to be aware of FP before they got married compared to those with intended pregnancies.

- Unintended pregnancies were more likely to result in spontaneous or induced abortion: There were significant variations in pregnancy outcomes by whether the pregnancies were intended or not. For instance, a higher proportion of unintended compared to intended pregnancies resulted in spontaneous or induced abortion ( $12 \%$ and $5 \%$ respectively). By contrast, a higher proportion of intended compared to unintended pregnancies resulted in a live birth (75\% and $66 \%$ respectively). 
- High levels of unmet need for FP among married adolescent girls in the urban slums: The level of unmet need for FP among married adolescent girls in the study (15\%) was higher than that of a similar group in all urban areas of Bangladesh (10\%) based on the 2011 Bangladesh Demographic and Health Survey. Unmet need was higher for spacing the births of children (12\%) than for limiting the number of children (3\%).

- High levels of discontinuation of FP method use for various reasons: Although a majority (85\%) of the married adolescent girls had used FP method before, only $58 \%$ were using a method at the time of the survey. Besides being currently pregnant and wanting to have a child, other reasons for discontinuing use of FP method were fear of side effects, opposition by the husband or other family members, and infrequent sex. Cost of methods was also cited as a major barrier to the method use.

\section{Recommendations}

\section{The study findings suggest the need to:}

- Conduct health education on FP among married adolescent girls in order to promote awareness and consistent use of effective contraceptives for birth spacing among this segment of the population with the goal of reducing high levels of unintended pregnancy.

- Develop community sensitization to marshal the support of family members and community opinion leaders for FP services for married adolescent girls.

- Improve counseling on FP for married adolescent girls and their spouses in order to clear some of the barriers to method use such as misconceptions and fear of side effects, and to ensure appropriate timing and consistent use of FP method.

- Ensure FP services are affordable for married adolescent girls and their spouses, for instance, through a standard demand-side financing (DSF) mechanism for the very poor.

- Target specific groups with family planning services such as those who are newly married, want to postpone their pregnancy at a later age, or want to space births or have reached their ideal family size. Spouses of the adolescent girls should also be targeted to elicit their support and participation in such programs. 


\section{Background}

Family planning (FP) allows individuals and couples to anticipate and attain their desired number of children and the spacing and timing of their births. On the contrary, unintended pregnancies (UP) are pregnancies that are reported to have been either unwanted (i.e. they occurred when no children or no more children were desired) or mistimed (i.e. they occurred earlier than desired) [1]. Globally, about 4 in 10 pregnancies are unintended and roughly half of these result in induced abortion. Unintended pregnancies in low and middle income countries are associated with high levels of maternal and child mortality and morbidity.

In countries with highly restrictive abortion laws, early, unwanted pregnancies are related to high rates of induced abortion often carried out in unsafe conditions, which can cause severe health problems, or even death [2]. UP is negatively associated with seeking antenatal care, breastfeeding behavior, and child nutrition [2]. Further, children who are the result of UP are at a higher risk of infant mortality than children from intended pregnancies [3].

UP among adolescents is an issue of global concern that has considerable implications for maternal, neonatal, and child health. Worldwide, $11 \%$ of all births are among girls aged $15-19$ years and approximately $95 \%$ of these occur in low- and middle-income countries [4]. Pregnancy at an early age carries health risks for both the mother and child. In low- and middle-income countries, complications of pregnancy and childbirth among adolescents represent $23 \%$ of the overall burden of disease and are the leading cause of death among girls aged 15-19 years [3]. Not only are early pregnancies more likely to be unwanted, they are also associated with many additional adverse health, social, and economic consequences. Evidence shows that adolescent pregnancy is correlated with pregnancy-related complications, preterm delivery, delivery of low birth weight babies, and spousal violence [5]. The broader social consequences of early pregnancy include lower educational attainment, limited ability to earn income, higher overall fertility rates, and marital and family difficulties [3]. Adolescents, therefore, are a particularly vulnerable group, both in terms of early childbearing and unintended pregnancy, although the context in which they live influences that vulnerability.

In Bangladesh, early marriage and early childbearing has led to an adolescent fertility rate that is among the highest in the world. The average age of marriage for girls is 14-15 years although the legal age of marriage for girls in Bangladesh is 18 years. There is still very strong social and family pressure for girls to marry at an early age and for them to prove their fertility soon after marriage. In addition to early marriage, lack of accessible family planning and reproductive health services in Bangladesh may also contribute to early childbearing. The 2011 Bangladesh Demographic and Health Survey (BDHS) showed that 1 in 5 births to girls aged less than 20 years were unintended, with about $96 \%$ of these unintended births being mistimed (wanted later) [6]. The $2011 \mathrm{BDHS}$ survey also showed that $17 \%$ of currently married girls aged $15-19$ years had an unmet need for $\mathrm{FP}$, with $15.7 \%$ having an unmet need for spacing births while 1.3\% having an unmet need for limiting births. Meanwhile, $59 \%$ of currently married girls of this age group had ever heard of menstrual regulation (MR), although only $2.6 \%$ had used MR services. Collectively, these factors contribute to the high rate of unintended pregnancy among adolescents.

Although research exists on overall UP and contraceptive use among married adolescent girls in Bangladesh, similar data that focuses on particularly vulnerable groups of adolescents is very limited. One such group is the married adolescent girls living in urban slums. Evidence shows that married girls aged 15-19 from slum areas are almost twice as likely to be mothers as girls from non-slum areas [7]. Reducing the overall burden of UP requires research that focuses specifically on the unique context of the married adolescent girls in urban slums. It is crucial to understand the factors that contribute to UP among this group, as well as the barriers to access and 
effective use of family planning (FP) and MR services, so that appropriate policies and interventions can be designed and implemented.

The overall aim of the study was to determine the prevalence of and the basic underlying factors of UP among married adolescent girls in urban slums in Bangladesh. The specific objectives of the study were to:

1) document the prevalence of unintended pregnancy among married adolescent girls aged 15-19 years living in urban slums;

2) identify the factors associated with or which contribute to unintended pregnancy among the married adolescent girls in urban slums;

3) estimate the proportion of married adolescent girls in urban slums who have an unmet need for FP services; and

4) explore the barriers to access and effective use of FP and MR services among married adolescent girls in urban slums of Dhaka, Bangladesh.

\section{Methods}

\section{Study design}

The study had two components:

Quantitative component: This was a population based cross-sectional survey of randomly selected married adolescent girls aged 15-19 years living in urban slums. The purpose of the survey was to determine the prevalence of UP among married adolescent girls, factors associated or contributing to these unintended pregnancies, the proportion with an unmet need for FP; and barriers to access and effective use of FP methods.

Qualitative component: This involved in-depth interviews (IDIs) with selected married adolescent girls (who had experienced at least one unintended pregnancy) and who were identified from the quantitative survey together with their husbands, regardless of the age of the husbands. The purpose of the interviews was to identify the factors associated with UP and the barriers to access and effective use of FP and MR services among the target population.

\section{Data collection}

The study was carried out in five purposively selected slum areas of Dhaka (Kamrangirchar, Shyampur, Rayerbazar, Shekhertek and Mirpur) during the period of May to September 2013. Slum areas were selected to ensure variation in number of years the slum has existed, the size of the slum, the type of land ownership, and the rates of outmigration.

\section{Quantitative survey}

A total of 1,008 married adolescent girls participated in the quantitative survey. Of these, equal numbers of the respondents were interviewed from the five selected urban slums. Six female Field Research Assistants (FRAs) were assigned for collecting quantitative data under the supervision of one female Field Research Supervisor (FRS). 
To select the households, interviewers started from a central location (such as school/mosque) in the slum using an existing map of the area provided by the BRAC Manoshi project ${ }^{1}$. The interviewers began by spinning a bottle at the central location to determine the first household based on the direction of the bottle. One eligible (eligibility criteria included 15-19 years aged married girls; duration of marriage must be more than 3 months and had been living in the slum for more than 1 month) respondent in each selected household was invited to participate in the study (if a selected household had two or more eligible respondents, all were interviewed). If no one in the selected household was eligible, the interviewer moved to the next household. If an eligible respondent lived in a selected household but was not available at that time, the interviewer obtained information on availability of the respondent from her family members (if available) or household members from their neighbors or the people adjacent to that household and returned again based on her availability. One additional visit was made before the respondent was replaced; if the eligible respondent is only available outside of work hours, she had been excluded from the sample. The entire process of sample selection was repeated until the required sample size of respondents was obtained. Mentally challenged or mentally disabled individuals were excluded from the survey.

Information was collected on the socio-demographic characteristics of the respondents (such as age, years of schooling and employment status), their knowledge and perceptions about FP, reproduction and pregnancy, FP practices, fertility preferences, spousal communication and on barriers of using FP services.

The distribution of respondents by background characteristics is presented in Table 1. Majority (59.9\%) of the respondents were between $18-19$ years of age, while about $2.0 \%$ were aged 14 years or below (though the age limitation of the respondents' was $15-19$ years but $2 \%$ of the respondents of below 15 years age group ie. up to 13 years, had been included in the sample due to some misinterpretation during their age declaration). Nearly one-fifth of the respondents (16.6\%) never attended school and one-tenth $(10.8 \%)$ had 9 or more years of schooling; less than one-fifth (15.9\%) of the respondents worked outside the home.

\footnotetext{
${ }^{1}$ BRAC Manoshi Project in Dhaka Metropolitan City: the Manoshi project was developed by BRAC to establish a community-based health programme targeted at reducing maternal and child mortality in the urban slums of Bangladesh. It addressed the Bill and Melinda Gates Foundation's Community Health Solutions (CHS) initiative that aimed at strengthening and leveraging community organizations and respondents to scale up proven interventions in community settings. Manoshi was implemented in the urban slums of six city corporations (Dhaka, Chittagong, Sylhet, Rajshahi, Barisal and Khulna) and in 15 statistical metropolitan areas of Dhaka to provide services to 8 million population. This five-year project (January 2007 to December 2011) was led and implemented by BRAC. icddr,b, in collaboration with the Research and Evaluation Division (RED) of BRAC, provided technical assistance to the project.
} 
Table 1: Percent distribution of respondents by background characteristics

\begin{tabular}{|c|c|}
\hline Characteristics & Percent ( $n=1008)$ \\
\hline \multicolumn{2}{|l|}{ Study area } \\
\hline Rayer Bazar & 19.8 \\
\hline Shekertek & 19.9 \\
\hline Kamrangir char & 20.2 \\
\hline Shaympur & 19.9 \\
\hline Mirpur & 20.0 \\
\hline \multicolumn{2}{|l|}{ Age of respondents (in years) } \\
\hline$\leq 14$ & 1.5 \\
\hline $15-17$ & 38.6 \\
\hline$\geq 18$ & 59.9 \\
\hline \multicolumn{2}{|l|}{ Age of respondents' husbands (in years) } \\
\hline $15-20$ & 13.2 \\
\hline $21-25$ & 59.7 \\
\hline $26-30$ & 23.7 \\
\hline $31-45$ & 3.4 \\
\hline \multicolumn{2}{|l|}{ Education of respondents (in completed years) } \\
\hline No education & 16.6 \\
\hline $1-5$ & 48.9 \\
\hline $6-8$ & 23.7 \\
\hline $9+$ & 10.8 \\
\hline \multicolumn{2}{|l|}{ Employment status of respondents } \\
\hline Yes & 15.9 \\
\hline No & 84.1 \\
\hline Types of Occupation of respondents & $n=161$ \\
\hline Government/private service & 5.6 \\
\hline Business & 4.4 \\
\hline Garment/factory worker & 34.8 \\
\hline Other services & 55.3 \\
\hline Age at marriage of respondents (in years) & $\mathrm{n}=1008$ \\
\hline$\leq 14$ & 42.9 \\
\hline $15-17$ & 52.8 \\
\hline$\geq 18$ & 4.4 \\
\hline \multicolumn{2}{|l|}{ Husband stays with respondent } \\
\hline${ }^{*}$ Stays regularly & 95.8 \\
\hline${ }^{* *}$ Stays irregularly & 4.2 \\
\hline \multicolumn{2}{|l|}{ Type of marriage of respondents } \\
\hline Love marriage & 39.4 \\
\hline Arranged marriage & 60.6 \\
\hline Consented to arranged marriage & $n=611$ \\
\hline Yes & 87.1 \\
\hline No & 12.9 \\
\hline
\end{tabular}

*Husband stays with the respondent regularly.

**Husband does not stay with the respondent and visits her once a week/month or bimonthly.

\section{Qualitative in-depth interviews}

Three couples from each slum who reported an unintended pregnancy were purposively selected for IDI based on key sampling criteria (e.g., mistimed or unwanted pregnancy, number of pregnancies, age, and education). We planned to conduct 30 in-depth interviews ( 15 females and 15 males) and finally managed 29 interviews (15 females and 14 males). Two qualitative researchers (one male and one female) analyzed the IDIs, which were conducted using a semi-structured interview guide that assessed factors associated with UP and the barriers to access and effective use of FP and MR services. 
Respondents who reported UP (either unwanted or mistimed) with some consequences (such as MR and/or abortion or continuation of the pregnancy) during the quantitative survey were informed about the possibility that they and their husbands might be included in the sample for the IDI at a later date. The interviewers also asked the respondent about her husband's willingness/consent to give an interview on this issue and the respondent's level of comfort with requesting her husband to participate in the IDI. If the respondent was not confident about her husband's participation in the IDI or she was found uncomfortable with her husband being approached for participation in the IDI, her name was removed from the tentative IDI sample list. While setting the IDI time with the respondent, interviewers enquired about a convenient time and contact information to arrange an appointment with her husband to conduct his IDI.

\section{Data Analysis}

\section{Quantitative data analysis}

All quantitative data were entered by trained personnel into a computer database using Oracle 10.0. Each survey respondent was assigned a unique identification number to ensure confidentiality. The quantitative data were analyzed using STATA version 11.1 (Stata, College Station, TX, USA). The primary outcomes of interest were UP and unmet need for FP. In this study, UP was defined as the proportion of respondents who were: pregnant at the time of the survey but wanted the pregnancy at a later time or did not want any more children at all. The operational definition of unmet need for FP was the proportion of respondents who were: not pregnant at the time of the survey, wanted to delay the next birth by two or more years but were not using any FP method as well as the proportion that was pregnant at the time of the survey but whose pregnancy was either wanted later or not wanted at all. Analysis involved cross-tabulations with chi-square tests to examine the association between UP and unmet need for FP with the socio-demographic characteristics of the respondents and their knowledge of FP, attitudes of FP use, and spousal communication with their husbands on fertility preferences. P-values less than 0.05 were considered statistically significant.

\section{Qualitative data analysis}

Analysis of qualitative data was an iterative and ongoing process that started during data collection. IDIs were tape recorded and transcribed into the local language (Bengali). Data analysis was carried out in English directly from the Bengali transcription of each of the IDI. Each IDI contained voluminous information therefore data were organized through repeated and systematic review of the transcripts linked to the research questions, specific objectives (objective 2 and 4 ) and other emerging issues. The process further involved continuous identification of themes, logical connections, and clarifications or relevant comments that matched or helped to explain similar statements made by other respondents. The data categorization process included the identification of salient themes and sub-themes, recurring ideas and local meanings. Researchers identified the common patterns that emerged from all interviews in order to explore the in depth factors associated with UP and unmet need for FP as well as MR/abortion. It also helped to note atypical patterns in order to accommodate the diversity of meaning and to generate new insights and typologies to be explored further. All complementary field notes were added to the transcribed data. Thematic analysis of data was done manually using content analysis and comparison between couple responses. Only those quotes that are presented to support the study findings were translated into English during analysis. 


\section{Ethical Considerations}

The study received ethical approval from the ethical review committee of icddr,b and the Population Council's Institutional Review Board. Written informed consent was obtained from each participating respondent. The consent process involved clearly explaining the purpose of the study, the type of information to be collected, the risks and benefits of participating in the study, the mechanisms for maintaining confidentiality of the information, their rights of voluntary participation and withdrawal, and sources of additional study-related information. According to Bangladesh law, the age of consent for participating in research is 18 years. A section of the adolescents (13-17 years) were therefore classified as minors. For these respondents, informed consent was sought at two levels - spouses/parents-in-law/guardians first, followed by the individual adolescents. Adolescents indicated their willingness to participate by assenting to the study after parents-in-law/guardians had given permission. Adolescents aged 18-19 years provided individual consent only. The consent forms were read out aloud by interviewers whereupon the respondents were asked if they agreed to participate in the study. Special care was taken to obtain voluntary and fully informed consent in all cases. Participation in the study was completely voluntary; respondents were not provided with any inducements or incentives.

\section{Results}

The results are organized into five parts based on the objectives that address a wide range and number of aspects of UP among the respondents. Part one covers the prevalence of UP among married adolescent girls in urban slums in Bangladesh; part two presents the factors associated with UP among this group; part three presents information on the consequences of UP; part four describes unmet need for FP services; and part five summarizes the barriers to access and effective use of FP and MR services among the target population.

\section{Part 1: Prevalence and Causes of UP}

\subsection{Prevalence of unintended pregnancy}

Among the total 1,008 respondents those participated in the survey, $783(78 \%)$ had ever been pregnant during their lifetime and more than half (56\%) of them reported an UP. In addition, a total of 942 pregnancies were reported by the respondents who had ever been pregnant with more than half $(53 \%)$ of the pregnancies being unintended (52.2\% were mistimed while $0.4 \%$ were unwanted).

\subsection{Causes of unintended pregnancy}

Almost one third (29\%) of the respondents who reported an UP stated about forgot to use a method, $15 \%$ were unknown of any method during the time of unintended conception, another $15 \%$ reported fear of side effects of methods and more than $11 \%$ stated about method failure. To fulfill husband's desire of taking a child mentioned by $11 \%$ of the respondents, $10 \%$ affirmed about mother-in-law's desire while more than $5 \%$ said about other family member's desire. Unavailability of method was reported as one of the causes of UP by around $7 \%$ of the respondents while more than $9 \%$ reported reasons like lack of knowledge of where to obtain a method, lack of money to buy method, and inconveniency of using a method. 


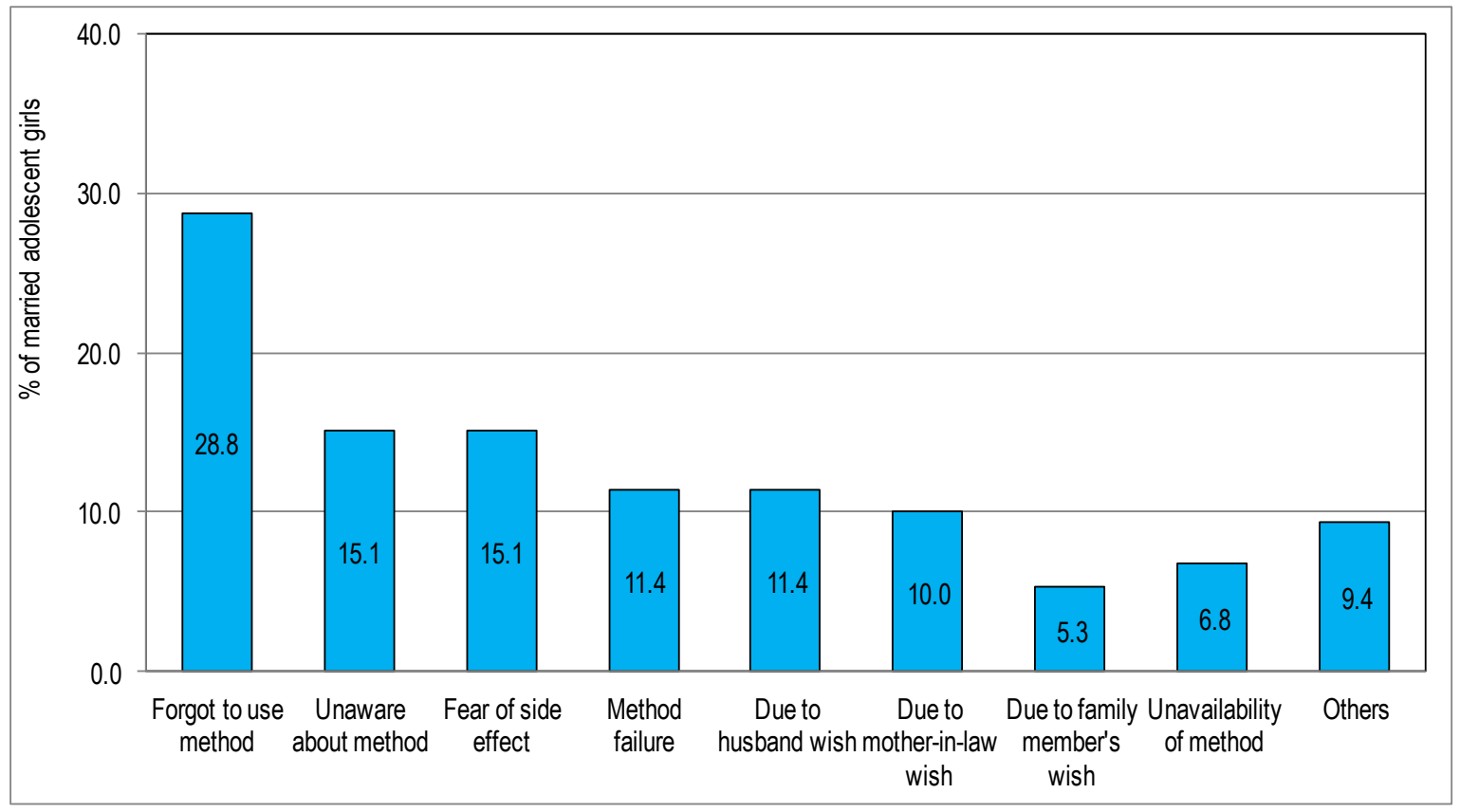

Other reasons for UP based on the IDIs with husbands of respondents included lack of spousal communication (a few husbands stated that they were not aware that their wives were not taking pill regularly); irregular use of FP methods by the wives; gaps between switching of methods (one respondent mentioned there was a one month gap before his wife started taking pill after switching from injections); and wrong calculation about the safe period. IDI with respondents also reported lack of proper knowledge on FP method use; discontinuation of methods due to side effects; and failure of natural methods (safe period/withdrawal) as reasons for UP. Some respondents also reported that they conceived against their wish because the husband wanted a child or elderly family members such as mother-in-law or father-in law wanted to have a grandchild.

\section{Part 2: Factors Associated with UP}

\subsection{Socio-demographic factors}

Table 2 summarizes the prevalence of UP based on socio-demographic characteristics of those respondents who had ever been pregnant $(n=783)$. There were significant variations in the prevalence of UP by study area $(p<0.01)$. In particular, the proportion of UP was more than twice higher among the respondents of Rayerbazar compared to those of Mirpur (71\% and 34\% respectively). Significant variations were also observed in the proportions of UP by respondents' age, type of occupation, and their agreement with arranged marriage (among those whose marriages were arranged). The prevalence of UP declined by increasing age of the respondents (from $100 \%$ among those aged less than 14 years to $52 \%$ among those aged 18 years and above; $p<0.01$ ). In addition, UP was highest among those who were involved in other services (such as maids, handicraft workers, day labourers, and cleaners) and lowest among those in business ( $63 \%$ and none respectively; $p<0.05$ ). UP was also higher among those who did not agree with arranged marriage than among those who agreed with arranged marriage $(73 \%$ and $54 \%$ respectively; $p<0.01)$. 
Table 2: Percent distribution of UP by respondents' socio-demographic characteristics

\begin{tabular}{|c|c|c|c|}
\hline Characteristics & $\begin{array}{c}\text { Number of respondents who have } \\
\text { ever been pregnant ( } n=783)\end{array}$ & $\begin{array}{l}\text { Percent with } \\
\text { UP }\end{array}$ & $p$-value \\
\hline \multicolumn{4}{|c|}{ 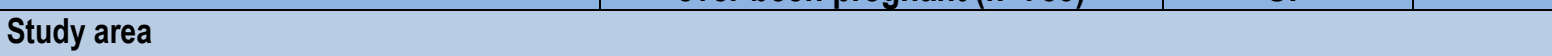 } \\
\hline Rayer Bazar & 156 & 70.5 & \\
\hline Shekertek & 155 & 65.8 & \\
\hline Kamrangir char & 163 & 62.6 & \\
\hline Shaympur & 152 & 46.1 & \\
\hline Mirpur & 157 & 34.4 & $<0.01$ \\
\hline \multicolumn{4}{|c|}{ Age of respondents (in years) } \\
\hline$\leq 14$ & 4 & 100.0 & \\
\hline $15-17$ & 264 & 63.3 & \\
\hline$\geq 18$ & 515 & 51.8 & $<0.01$ \\
\hline \multicolumn{4}{|c|}{ Education of respondents (in years) } \\
\hline No education & 140 & 64.3 & \\
\hline $1-5$ & 412 & 54.9 & \\
\hline $6-8$ & 163 & 55.8 & \\
\hline $9+$ & 68 & 45.6 & 0.07 \\
\hline \multicolumn{4}{|c|}{ Employment status of respondents } \\
\hline Employed & 116 & 57.8 & \\
\hline Not employed & 667 & 55.6 & 0.70 \\
\hline \multicolumn{4}{|c|}{ Types of occupation of respondents } \\
\hline Govt./Private service & 8 & 50.0 & \\
\hline Business & 6 & 0.0 & \\
\hline Garment/factory workers & 32 & 59.4 & \\
\hline Other services & 70 & 62.9 & 0.03 \\
\hline \multicolumn{4}{|c|}{ Age at marriage of respondents (in years) } \\
\hline$\leq 14$ & 373 & 59.0 & \\
\hline $15-17$ & 396 & 53.5 & \\
\hline$\geq 18$ & 14 & 42.9 & 0.20 \\
\hline \multicolumn{4}{|c|}{ Types of marriage of respondents } \\
\hline Love marriage & 301 & 55.2 & \\
\hline Arranged marriage & 482 & 56.4 & 0.73 \\
\hline \multicolumn{4}{|c|}{ Agreement on arranged marriage } \\
\hline Yes & 416 & 53.9 & \\
\hline No & 66 & 72.7 & $<0.01$ \\
\hline \multicolumn{4}{|l|}{ Age of husbands (in years) } \\
\hline$\leq 19$ & 18 & 77.8 & \\
\hline $20-24$ & 332 & 58.7 & \\
\hline $25-29$ & 349 & 53.6 & \\
\hline$\geq 30$ & 84 & 50.0 & 0.09 \\
\hline \multicolumn{4}{|c|}{ Age differences between husbands and wives (in years) } \\
\hline 1 & 12 & 41.7 & \\
\hline $2-5$ & 252 & 61.5 & \\
\hline $6-10$ & 421 & 53.9 & \\
\hline$>10$ & 98 & 52.0 & 0.14 \\
\hline
\end{tabular}

The results in Table 2 further show that about two-thirds $(64.3 \%)$ of the respondents who never attended school had an UP. The proportion of respondents reporting UP declined with increasing years of schooling although the difference was not statistically significant $(p=0.07)$. Similarly, the prevalence of UP was highest among those who married before age 14 and lowest among those who married at age 18 or higher although the difference was not statistically significant ( $59 \%$ and $43 \%$ respectively; $p=0.20$; Table 2 ). 
Further analysis showed significant variations in the distribution of UP by the age of the respondent at the time of conception. The prevalence of UP declined with increasing age at conception; it was $64 \%$ among those who became pregnant at the age of 14 years or younger, $52 \%$ among those who became pregnant at ages $15-17$ years and $45 \%$ among those who became pregnant at the age of 18 years or older (Figure 2).

Figure 2: Percent distribution of UP by respondent's age at conception

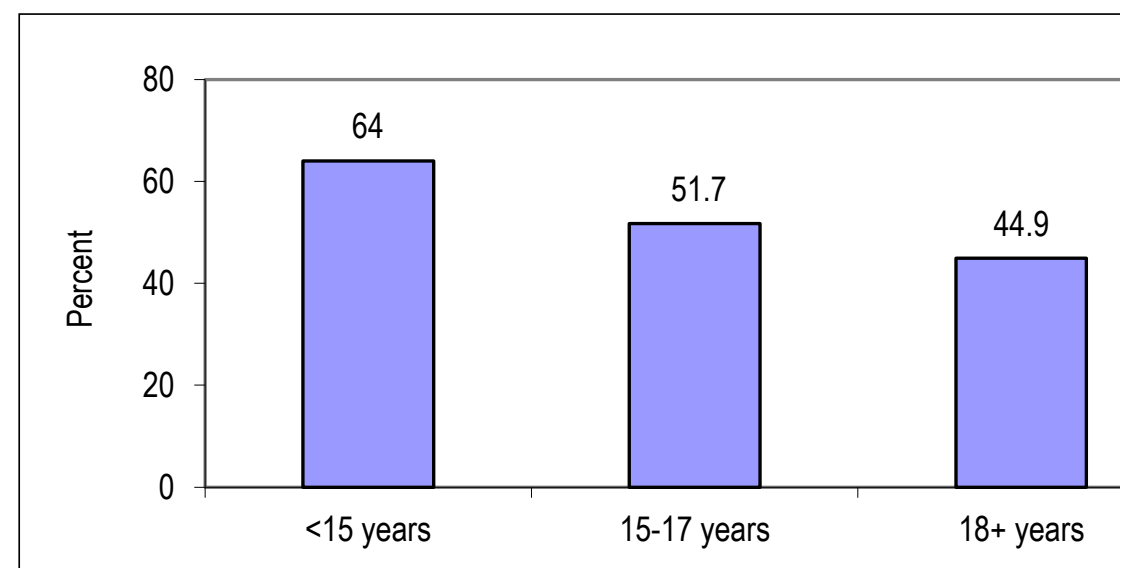

\subsection{Knowledge and perception of respondents' about marriage, childbirth and FP}

Table 3 summarizes the prevalence of UP by respondents' knowledge and attitudes to FP as well as perceptions about appropriate child spacing, age at first marriage and first birth for females. There were significant variations in the prevalence of UP by respondents' perceptions about the ideal age at first birth for females $(p<0.01)$. The proportion of respondents with UP was higher among those who felt that the ideal age at first birth should be less than 18 years than among those who indicated that the ideal age should 18 years or higher ( $80 \%$ and $57 \%$ respectively). There were, however, no significant differences in the prevalence of UP by the other indicators of knowledge and perceptions considered (Table 3).

Table 3: Prevalence of UP by respondents' knowledge and perceptions about marriage, childbirth, and FP

\begin{tabular}{|l|r|r|r|}
\hline \multicolumn{2}{|l|}{$\begin{array}{r}\text { No. of respondents } \\
\text { who have ever been } \\
\text { pregnant (n=783) }\end{array}$} & $\begin{array}{r}\text { Percent with } \\
\text { UP }\end{array}$ & -value \\
\hline \multicolumn{2}{|c|}{ A. Perceptions of respondents about ideal age at marriage for a female } \\
\hline$<18$ & 27 & 51.9 & \\
\hline$\geq 18$ & 748 & 56.7 & 0.619 \\
\hline Ideal age at first childbirth for a female & & & \\
\hline$<18$ & 5 & 80.0 & \\
\hline$\geq 18$ & 733 & 57.4 & \\
\hline Don't know & 45 & 28.9 & $<0.001$ \\
\hline Ideal time interval between two pregnancies (in years) & & & \\
\hline$\leq 2$ & 34 & 55.9 & \\
\hline $3-5$ & 552 & 56.5 & \\
\hline$>5$ & 197 & 54.3 & 0.866 \\
\hline B. Currently knows about FP methods & & & \\
\hline Yes & 783 & 56.0 & \\
\hline No & 0 & 0.0 & \\
\hline C. Supports FP method use & & & \\
\hline Yes & 753 & 56.7 & \\
\hline No & 25 & 40.0 & \\
\hline No opinion & 4 & 25.0 & 0.116 \\
\hline
\end{tabular}


Figures 3 and 4 present the distribution of married adolescent girls with and without unintended pregnancy by knowledge of family planning and emergency pills before marriage. Interestingly, married adolescent girls with unintended pregnancy were more likely to be aware of family planning before they got married compared to those with intended pregnancies. The proportion that knew of family planning before marriage was higher among married adolescent girls with unintended than among those with intended pregnancies $(71 \%$ and $78 \%$ respectively; Figure 3). Similarly, the proportion with knowledge of emergency pills before marriage was higher among those with unintended than among those with intended pregnancies (91\% and $95 \%$ respectively; Figure 4).

Figure 3: Knowledge about FP (before marriage) among respondents with unintended and intended pregnancies

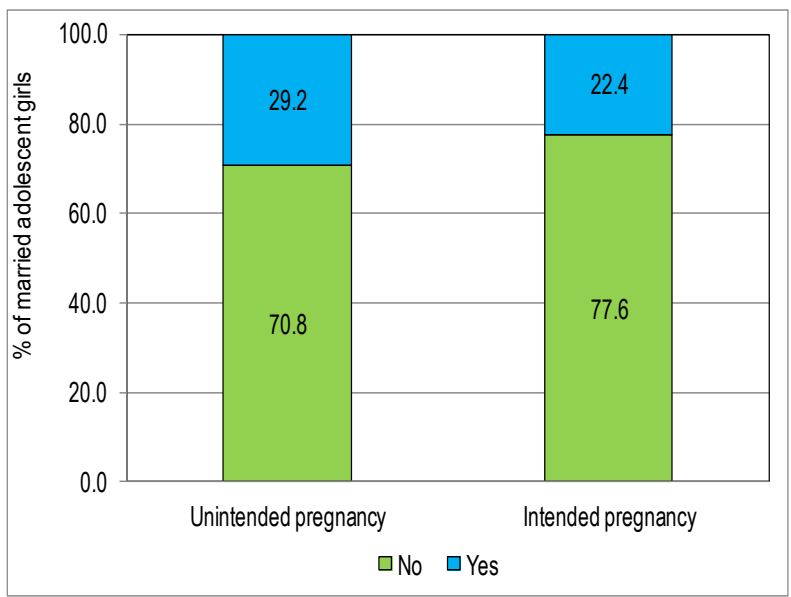

Figure 4: Knowledge about ECP (before marriage) among respondents with unintended and intended pregnancies

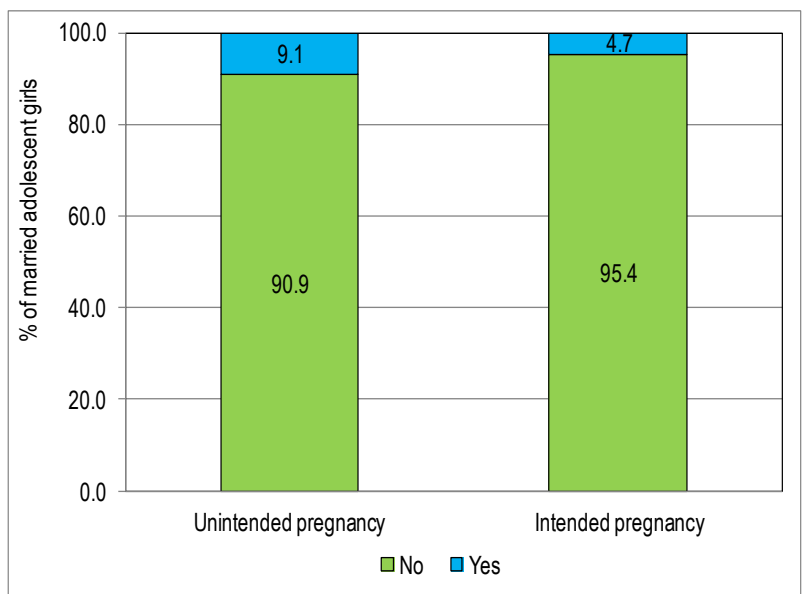

Insights from IDIs with husbands of respondents showed that most of them knew about FP methods such as condoms, oral contraceptive pills (OCP) and injectables. Major sources of information of condom, OCP and safe period (before marriage) were their friends. Six out of fourteen husbands heard about injectables after marriage whereas only two of them heard about them before marriage and the sources of information were their wives and older friends. Fewer knew about implants and the major source of information on implants was older friends in their neighborhood; other sources of information included health centres managed by non-governmental organizations (NGO), health workers, pharmacies and some books. IDI with respondents showed similar patterns regarding knowledge and source of modern FP methods. While very few of the respondents were aware about natural methods (safe period and withdrawal) and the failure of these methods was one of the major reasons for experiencing their UP.

\subsection{Spousal agreement on fertility preferences and unintended pregnancy}

Table 4 presents the prevalence of UP by spousal agreement on childbearing. Significant association was observed in the proportion of UP by whether the respondents agreed with their spouses about future childbearing $(p<0.01)$. The prevalence of UP was highest among those who agreed with their spouses not to have any children in future and lowest among those who agreed to have children in future ( $78 \%$ and $51 \%$ respectively). There were, however, no significant association in the prevalence of UP and spousal agreement on the number of children planned and sex composition of the children. 
Table 4: Prevalence of UP by spousal agreement on childbearing

\begin{tabular}{|c|c|c|c|}
\hline & $\begin{array}{l}\text { No. of respondents who have } \\
\text { ever been pregnant ( } n=783)\end{array}$ & $\begin{array}{l}\text { Percent with } \\
\text { UP }\end{array}$ & $\mathrm{p}$-value \\
\hline \multicolumn{4}{|l|}{ Plan to have children in future } \\
\hline Agreed to have children & 601 & 50.9 & \\
\hline Agreed not to have children & 113 & 77.9 & \\
\hline $\begin{array}{l}\text { Disagreed on whether to have } \\
\text { children or not }\end{array}$ & 69 & 63.8 & $<0.01$ \\
\hline \multicolumn{4}{|l|}{ Plan on number of children } \\
\hline Agreed on number of children & 548 & 50.9 & \\
\hline Disagreed on number of children & 53 & 50.9 & 0.99 \\
\hline \multicolumn{4}{|l|}{ Plan on number of sons } \\
\hline Agreed on number of sons & 553 & 51.4 & \\
\hline Disagreed on number of sons & 38 & 44.7 & 0.43 \\
\hline \multicolumn{4}{|l|}{ Plan on number of daughters } \\
\hline Agreed on number of daughters & 562 & 51.4 & \\
\hline Disagreed on number of daughters & 29 & 41.4 & 0.29 \\
\hline
\end{tabular}

\subsection{Perceptions about responsibility of using FP methods}

The prevalence of UP was highest among those respondents who felt that it was the joint responsibility of both husband and wife to make decisions about the use of FP and lowest among those who thought it was only the wife's responsibility ( $62 \%$ and $45 \%$ respectively; Figure 5$)$.

Figure 5: Prevalence of UP by perceptions about responsibility for FP method use

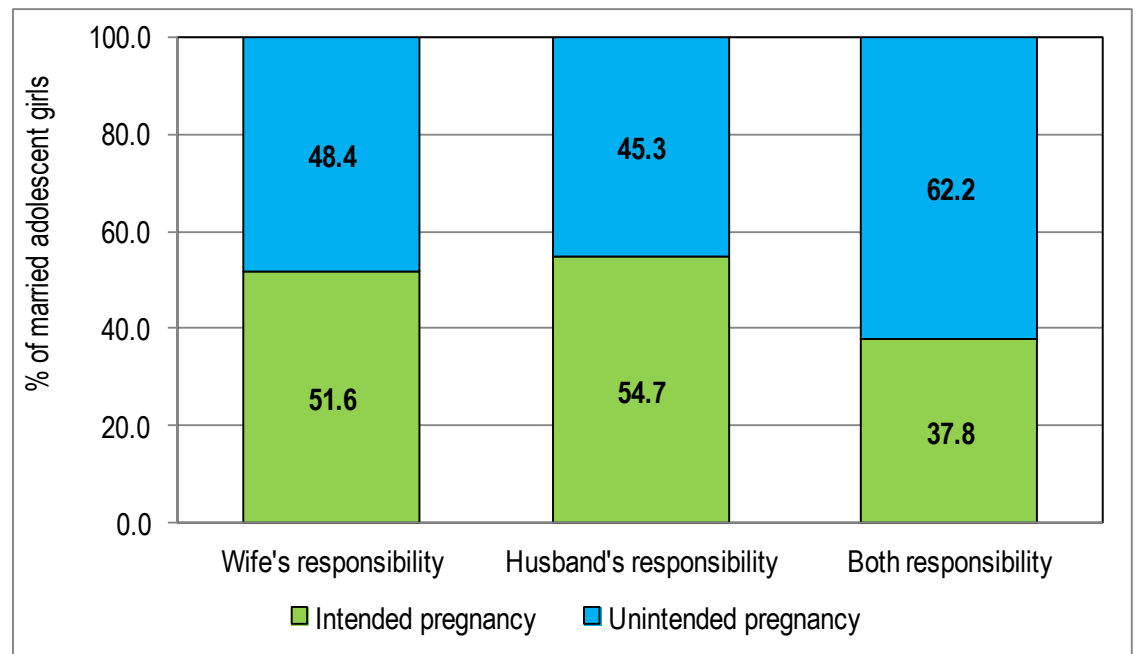

Findings from IDIs showed that ten out of fourteen husbands of the respondents felt that it was their (husbands') sole responsibility to use FP methods. They noted that wives are usually very busy with their household activities and sometimes forgot to take oral pills regularly and it was easier for the man to remember to use a condom. Similarly, most of the wives mentioned that it was the husband's responsibility to use FP method or make decision regarding the use of methods as husbands play a dominating role in the family. The following excerpts support these findings:

"If I think I should keep my family small then it is the responsibility of the male and if male member thinks that he will keep his family big then there is no need to use it. But I think males should use family planning methods in order to keep family size small." (IDI, husband) (Age 19 years, 0 years of education, Business person) 
"If a husband does not want to use any family planning method by himself or does not give permission to his wife to use one, then a woman cannot use any family planning method even if she eagerly wants to use one for birth control." (IDI, female) (Age 18 years, 9 years of education)

A few husbands felt that it was their wives' responsibility to use FP methods and to ensure consistent use. They noted that male partners may forget to remind their wives about the correct timing of taking pills or injectables but females are likely to remember it. Besides that, males always work outside home and sometimes become late to get back home but females usually stay at home and they should have enough time to take FP methods regularly in time. It was further noted that males have fewer FP method options than females. These findings are supported by the following quotes:

"Women are responsible for using family planning methods since it's their concern. If any woman misses a dose of pill, I will not be responsible for that. It is her responsibility to take it regularly and my responsibility is to bring it." (IDI, husband) (Age 26 years, 2 years of education, Van Puller)

"We are always busy with our income generating activities. We usually come back home at $12 \mathrm{pm}$ or even at $1 \mathrm{am}$. But she stays at home all the time; she does not do any services and she can take FP methods regularly." (IDI, husband) (Age 23 years, 2 years of education, Business person)

Few IDI participants (both male and female) felt that the husband and wife are equally responsible for using any FP method. One husband who thought that both spouses were responsible for using FP methods noted that young people need to be careful about any unwanted pregnancy and should wait until reaching an appropriate age for child bearing. Despite these opinions, the findings further showed that most of the husbands reported discussing the use of FP methods with their wives. Topics discussed included selection of methods, method switching, and birth spacing.

\section{Part 3: Consequences of Unintended Pregnancies}

\subsection{Health outcomes of unintended pregnancies}

Table 5 presents the distribution of intended and unintended pregnancies by various health outcomes. There were significant associations in pregnancy outcomes by whether they were intended or not $(p<0.01)$. In particular, the proportion of pregnancies that resulted in live births was higher among intended than among unintended pregnancies ( $75 \%$ and $66 \%$ respectively). By contrast, the proportion of pregnancies that resulted in abortion (spontaneous or induced) was twice higher among unintended than in intended pregnancies $(12 \%$ and $5 \%$ respectively).

Table 5: Percent distribution of intended and unintended pregnancies by various health outcomes

\begin{tabular}{|c|c|c|c|c|}
\hline & $\begin{array}{l}\text { Intended pregnancies } \\
(\%)(n=446)\end{array}$ & $\begin{array}{l}\text { Unintended pregnancies } \\
\qquad(\%)(n=496)^{a}\end{array}$ & $\begin{array}{l}\text { All pregnancies (\%) } \\
(n=942)\end{array}$ & $p$-value \\
\hline \multicolumn{5}{|l|}{ Pregnancy outcomes } \\
\hline Live births & 74.7 & 65.7 & 70.0 & $<0.01$ \\
\hline Still births & 2.5 & 1.2 & 1.8 & \\
\hline Spontaneous abortions & 4.7 & 6.1 & 5.4 & \\
\hline Induced abortions & 0.2 & 6.1 & 3.3 & \\
\hline Currently pregnant & 17.9 & 21.0 & 19.5 & \\
\hline
\end{tabular}




\subsection{Spousal intentions and outcomes of unintended pregnancies}

The effect of spousal intentions on pregnancy outcomes based on IDIs is shown in Table 6 . Out of 26 pregnancies reported by the fifteen respondents, five pregnancies were wanted by the respondents' while the remaining twenty one were unwanted or mistimed. According to their husbands, on the other hand, ten of the pregnancies were wanted and the rest were unwanted or mistimed. In 9 out of 12 pregnancies where both the wife and husband agreed that the pregnancy was unintended, they terminated the pregnancy through induced abortion. In contrast, only 2 out of 9 pregnancies where only the respondents' reported that the pregnancies were unintended and terminated through induced abortion. In the first instance, the husband was unaware about the pregnancy and in the second, the respondent made the decision to terminate the pregnancy although the husband reported the pregnancy as wanted. Five of the pregnancies were continued which were found mistimed according to the respondents' while it was wanted by their husbands. Table 6 shows that the decision about continuing the pregnancy does not always depend on the husband and the wife only. In two cases, both husbands and wives did not want to continue the pregnancy but the respondents had to continue their pregnancy since their mothers/mothers-in-law wanted the child.

Table 6: Spousal intentions and pregnancy outcomes at a glance

\begin{tabular}{|c|c|c|c|c|c|}
\hline $\begin{array}{l}\text { Case } \\
\text { No. }\end{array}$ & $\begin{array}{l}\text { No. of } \\
\text { Pregnancy }\end{array}$ & $\begin{array}{l}\text { Respondent's } \\
\text { opinion }\end{array}$ & $\begin{array}{l}\text { Respondent's } \\
\text { Husband's opinion }\end{array}$ & Pregnancy Outcome & $\begin{array}{l}\text { Whose decision got } \\
\text { priority }\end{array}$ \\
\hline \multirow{2}{*}{01} & 1st Pregnancy & Wanted & Wanted & Baby was born & Both \\
\hline & $2^{\text {nd }}$ Pregnancy & Unwanted & Mistimed & Induced Abortion & Both \\
\hline \multirow{3}{*}{02} & 1st Pregnancy & Wanted & Mistimed & Baby was born & Wife \\
\hline & $2^{\text {nd }}$ Pregnancy & Mistimed & Mistimed & Induced Abortion & Both \\
\hline & $3^{\text {rd }}$ Pregnancy & Mistimed & Didn't know about it & Currently pregnant & Wife \\
\hline 03 & 1st Pregnancy & Mistimed & Wanted & Currently pregnant & Husband \\
\hline \multirow{2}{*}{04} & 1st Pregnancy & Mistimed & Didn't know about it & Induced Abortion & Wife \\
\hline & $2^{\text {nd }}$ Pregnancy & Mistimed & Mistimed & Baby was born & Mother-in-law \\
\hline \multirow{3}{*}{05} & 1st Pregnancy & Mistimed & Mistimed & Induced Abortion & Both \\
\hline & $2^{\text {nd }}$ Pregnancy & Mistimed & Mistimed & Induced Abortion & Husband \\
\hline & 3rd Pregnancy & Mistimed & Wanted & Currently Pregnant & Both \\
\hline 06 & 1st Pregnancy & Mistimed & Mistimed & Induced Abortion & $\begin{array}{l}\text { Wife made decision } \\
\text { without informing husband }\end{array}$ \\
\hline \multirow{2}{*}{07} & $1^{\text {st }}$ Pregnancy & Mistimed & Mistimed & Baby was born & Mother \\
\hline & $2^{\text {nd }}$ Pregnancy & Mistimed & Mistimed & Induced Abortion & Both \\
\hline 08 & 1st Pregnancy & Mistimed & Mistimed & Induced Abortion & Both \\
\hline \multirow{3}{*}{09} & 1st Pregnancy & Wanted & Didn't Know about it & Spontaneous Abortion & Wife \\
\hline & $2^{\text {nd }}$ Pregnancy & Wanted & Wanted & Live birth & Both \\
\hline & $3^{\text {rd }}$ Pregnancy & Mistimed & Mistimed & Still birth & Both \\
\hline \multirow[t]{2}{*}{10} & 1st Pregnancy & Mistimed & Wanted & Induced Abortion & $\begin{array}{l}\text { Wife made decision } \\
\text { without informing husband }\end{array}$ \\
\hline & $2^{\text {nd }}$ Pregnancy & Mistimed & Wanted & Currently Pregnant & Both \\
\hline \multirow{2}{*}{11} & 1st Pregnancy & Mistimed & Wanted & Baby was born & Both \\
\hline & $2^{\text {nd }}$ Pregnancy & Unwanted & Mistimed & Induced Abortion & Both \\
\hline 12 & 1st Pregnancy & Mistimed & Mistimed & Induced Abortion & Both \\
\hline 13 & 1st Pregnancy & Mistimed & Wanted & Baby was born & Both \\
\hline \multirow{2}{*}{14} & $1^{\text {st }}$ pregnancy & Mistimed & Wanted & Spontaneous abortion & Both \\
\hline & $2^{\text {nd }}$ pregnancy & Wanted & Wanted & Baby was born & Both \\
\hline \multicolumn{6}{|c|}{ Respondent and her husband's opinion: Not similar } \\
\hline & & & & & \\
\hline
\end{tabular}


Insights from IDI of the respondents showed that the majority of them discussed their pregnancies with their husbands. Some respondents mentioned that the decision to continue the pregnancy or to terminate it is almost always depended on their husbands. A few respondents said that they had to continue their unintended pregnancies due to pressure from their mother-in-law, even though they were too young for childbearing and wanted to terminate the pregnancy. On the other hand, a few respondents said that they shared information or solicited opinions from their husbands or in-laws as to whether they should continue or terminate their pregnancies even if they thought it was entirely their own decision. In one case, the woman's in-laws and husband were reluctant to continue her first pregnancy but she was determined to continue with it. The following excerpts highlight some of these findings:

"When we (husband and wife) were confirmed about the pregnancy, he told me to discontinue it. What I could do then! As he did not want the baby, it was not possible for me to continue the pregnancy against his wish. If I would continue the pregnancy without his consent, he would send me to my natal family for this reason." (IDI, female) (Age 17 years, 4 years of education)

"I did not want to abort whereas my husband and mother-in-law were in favor of MR because of our financial hardship; it was difficult to manage our own food for survival. However, my neighbours suggested that I keep the baby as it was my first pregnancy. I was scared because they told me if I abort the baby then I might not be able to conceive in the future. Moreover, I thought if I have a baby then my in-laws will be happy and will behave well with me; but I was helpless." (IDI, female) (Age 17 years, 0 years of education)

The influence of parents or parents-in-law was also evident from the IDIs with husbands. A husband stated that he and his wife thought of doing MR to terminate his wife's pregnancy, but once his mother became aware of it, she (the mother) created pressure to them to continue the pregnancy. Another husband said that his mother-inlaw warned him against pregnancy termination, saying that she would file a case against him (the husband) if anything happened with her daughter during pregnancy termination. The husband then got afraid and agreed with his mother-in-law and allowed his wife to continue the pregnancy. However, some husbands did not have problems with continuing their wives' pregnancy even if it was unintended. As one of them noted:

"There was nothing to do as my wife was already pregnant; it could be terminated but that would not be fair, there was no problem as we are newly married couple. We need children. Let the baby come, we will take another one after 10 years." (IDI, husband) (Age 23 years, 10 years of education, Business person)

IDI participants gave various reasons of discontinuing the pregnancies. These included the need to avoid: (i) having another baby within a short interval given that the elder child was young, and (ii) physical problems associated with early pregnancy and childbirth. Four out of eleven husbands whose wives reported unintended pregnancies stated that they made the decision to use MR immediately after the wives missed their period. In three of the cases, the husbands did not know the exact time of pregnancy termination as their wives did so without informing them. In most cases, however, husbands reported that terminating an unintended pregnancy was a joint decision. Ten husbands, for instance, said that both husband and wife were involved in the decision making to terminate pregnancies that their wives considered unintended.

During the qualitative interviews, we explored the events that took place after respondents' perceived their pregnancies as unintended. We did IDIs with both the respondents' and their husbands and found discrepancies in the perception about the pregnancy (whether it was intended or unintended). Findings showed that sometimes when it was perceived as unintended by the respondent, the husband perceived it as intended. Also, when we 
asked respondents about the outcome of their unintended pregnancies, it was found that some respondents continued their pregnancies while others made decision of pregnancy terminating their using MR with MVA (Manual vacuum aspiration) or MR with medication (MRM) services. Most of the respondents stated that decision for continuing or discontinuing the pregnancy depended mostly on their husband's opinion. Among the 15 IDI respondents, 10 terminated at least one of their pregnancies. To justify this, they mentioned several reasons including being too young to get pregnant, financial hardship in the family, earlier child was too young to have another child, and wanted to carry on their education. Some respondents also mentioned that after going through the MR procedure they did not disclose this to their neighbor as they feared to face the social stigma as well as their neighbor might breach their confidentiality during a quarrel by disclosing this information to others.

Furthermore, some of the respondents wanted to terminate their pregnancy but did not succeed due to husbands and family pressure, especially pressure from their mother in-law.

\section{Part 4: Unmet Need for Family Planning}

Married adolescent girls who were not pregnant at the time of the survey, wanted to delay the next birth by two or more years but were not using any family planning method as well as those who were pregnant at the time of the survey but whose pregnancy was either wanted later or not wanted at all were considered to have unmet need for family planning. Fifteen percent of the respondents had an unmet need for FP with $12 \%$ having unmet need for spacing and 3\% for limiting births (Table 7). There was no significant association among the respondents who had an unmet need for FP by most of the socio-demographic characteristics considered. However, unmet need was significantly higher among those whose marriages were arranged but did not agree to it than among those who agreed with arranged marriages ( $25 \%$ and $14 \%$ respectively; $p<0.05$ ). In addition, unmet need was significantly higher among those whose husbands irregularly stayed with them compared to those whose husbands were regularly stayed with them in the same household ( $45 \%$ and $14 \%$ respectively; $p<0.01$ ). 
Table 7: Percent distribution of respondents with unmet need for FP and currently using a method by sociodemographic characteristics

\begin{tabular}{|c|c|c|c|c|c|}
\hline Characteristics & $\begin{array}{l}\text { Number of married } \\
\text { adolescent girls (n) }\end{array}$ & $\begin{array}{c}\% \text { of } \\
\text { unmet need }\end{array}$ & p-value & $\begin{array}{l}\% \text { of currently } \\
\text { using FP method }\end{array}$ & p-value \\
\hline \multicolumn{6}{|l|}{ Study area } \\
\hline Rayer Bazar & 200 & 16.5 & & 57.5 & \\
\hline Shekertek & 201 & 15.9 & & 58.2 & \\
\hline Kamrangir char & 204 & 14.7 & & 56.9 & \\
\hline Shaympur & 201 & 17.4 & & 56.7 & \\
\hline Mirpur & 202 & 11.4 & 0.49 & 61.4 & 0.38 \\
\hline \multicolumn{6}{|l|}{ Age of respondents (in years) } \\
\hline$\leq 14$ & 15 & 20.0 & & 53.3 & \\
\hline $15-17$ & 389 & 15.4 & & 53.7 & \\
\hline$\geq 18$ & 604 & 14.9 & 0.85 & 61.1 & $<0.05$ \\
\hline \multicolumn{6}{|c|}{ Education of respondents (in years) } \\
\hline No education & 167 & 20.4 & & 54.5 & \\
\hline $1-5$ & 493 & 14.2 & & 57.6 & \\
\hline $6-8$ & 239 & 14.2 & & 59.8 & \\
\hline $9+$ & 109 & 13.8 & 0.42 & 62.4 & 0.11 \\
\hline \multicolumn{6}{|c|}{ Employment status of respondents } \\
\hline Yes & 161 & 11.8 & & 64.0 & \\
\hline No & 847 & 15.8 & 0.19 & 57.0 & 0.26 \\
\hline \multicolumn{6}{|c|}{ Occupational status of respondents } \\
\hline Government/private service & 9 & 0.0 & & 44.4 & \\
\hline Business & 7 & 0.0 & & 85.7 & \\
\hline Garment/factory worker & 56 & 12.5 & & 55.4 & \\
\hline Other services & 89 & 13.5 & 0.42 & 69.7 & 0.29 \\
\hline \multicolumn{6}{|c|}{ Age at marriage of respondent (in years) } \\
\hline$\leq 14$ & 432 & 18.1 & & 63.2 & \\
\hline $15-17$ & 532 & 12.8 & & 55.5 & \\
\hline$\geq 18$ & 44 & 15.9 & 0.08 & 40.9 & $<0.01$ \\
\hline \multicolumn{6}{|c|}{ Types of marriage of respondents } \\
\hline Love marriage & 397 & 13.4 & & 55.9 & \\
\hline Arranged marriage & 611 & 16.1 & 0.19 & 59.6 & 0.52 \\
\hline \multicolumn{6}{|c|}{ Agreement on arranged marriage of respondents } \\
\hline Yes & 532 & 15.2 & & 60.0 & \\
\hline No & 79 & 24.1 & $<0.05$ & 60.0 & 0.06 \\
\hline \multicolumn{6}{|c|}{ Husband stays with respondents } \\
\hline Stays regularly & 966 & 13.9 & & 59.5 & \\
\hline Stays irregularly & 42 & 45.2 & $<0.01$ & 26.1 & $<0.01$ \\
\hline
\end{tabular}

Among the respondents who had an unmet need for FP, the most commonly cited reasons for not using a method included missed period (38\%), not having or infrequent sex with husband (19\%), fear of side effects (19\%), postpartum amenorrheoa (14\%), opposition by husband (7\%) and breastfeeding (9\%) [Table 8]. 
Table 8: Percent distribution of respondents with unmet need for FP by reasons for not using FP methods

\begin{tabular}{|l|c|}
\hline Reasons for not using FP methods* & Percent $(\mathbf{n}=153)$ \\
\hline Missed period due to some reason & 37.9 \\
\hline Not having or infrequent sex & 19.0 \\
\hline Fear of side effects & 15.0 \\
\hline Postpartum amenorrheic (up to 42 days) & 13.7 \\
\hline Husband opposed & 6.5 \\
\hline Breast feeding & 9.2 \\
\hline Other** & 10.5 \\
\hline $\begin{array}{l}{ }^{*} \text { Question allowed for multiple responses; } \\
\text { *Other included: Others opposed, fatalistic, knows no source, knows no method, respondent opposed, costs too much, inconvenient to use and religious } \\
\text { prohibition. }\end{array}$ \\
\hline
\end{tabular}

Most (92\%) of those with unmet need for FP approved the use of family planning [Table 9]. The most commonly cited reasons for approving the use of FP were the health of the mother (59\%), economic reasons (53\%), and to allow for spacing between births (49\%) [Table 9].

Table 9: Percent distribution of married adolescent girls with unmet need for family planning by indicators of support for method use

\begin{tabular}{|l|c|}
\hline Support for FP method use & Percent $(\mathbf{n}=\mathbf{1 5 3})$ \\
\hline Approve & 91.5 \\
\hline Disapprove & 7.2 \\
\hline No opinion & 1.3 \\
\hline Reason respondent approves of family planning* & Percent $(\mathbf{n}=\mathbf{1 4 0})$ \\
\hline For the health of the mother & 59.3 \\
\hline Economic reasons & 52.9 \\
\hline Spacing between two births allows taking care of the baby & 49.3 \\
\hline For the health of children & 15.7 \\
\hline${ }^{*}$ Question allowed for multiple responses \\
\hline
\end{tabular}

\section{Part 5: Barriers to Access and Effective Use of FP and MR Services}

\subsection{Use of family planning}

The majority ( $85 \%$ ) of the respondents used a FP method at some point in their lifetime. Among those who had used a method, $52 \%$ used it within the first 15 days of marriage while the remaining used a method after 15 days of marriage (Table 10$)$. It was usually the respondents $(78 \%)$ rather than their husbands who used a method. About one-fifth (22\%) of the respondents did not use a method before having their first child. Among those who used a method after having children, $88 \%$ used after getting one child while $12 \%$ used after getting two children. More than half (58\%) of the respondents were using a method at the time of the survey. The most common methods used by respondents included pill (41\%), injectables (33\%), and condom (13\%). Periodic abstinence, Norplant, male sterilization, and IUD were not as widely used (Table 10). 
Table 10: Percent distribution of respondents who had used FP by timing of use and types of method

\begin{tabular}{|l|c|}
\hline Timing of use of FP method & Percent $(\mathbf{n}=861)$ \\
\hline Within first 15 days of marriage & 52.0 \\
\hline After 15 days of marriage & 48.0 \\
\hline Use of method after having child & $\mathbf{n}=188$ \\
\hline After having their first child & 88.0 \\
\hline After having their two children & 12.0 \\
\hline Current use of FP method & $\mathbf{n = 1 0 0 8}$ \\
\hline Respondents currently using method & 58.1 \\
\hline Types of method currently used & $\mathbf{n}=587$ \\
\hline Pill & 40.8 \\
\hline Injectables & 32.9 \\
\hline Condom & 12.6 \\
\hline Periodic abstinence & 5.3 \\
\hline Norplant & 3.9 \\
\hline Male sterilization & 0.7 \\
\hline IUD & 0.3 \\
\hline
\end{tabular}

Slightly more than one-quarter (27\%) of the respondents had discontinued method use while $15 \%$ had never used a method (Table 11). Among those who had discontinued method use, the most frequently mentioned reasons for stopping use include: became pregnant (45\%), wanted to have a child $(21 \%)$, missed period $(16 \%)$, experienced side effects (9\%), infrequent sex with husband (8\%), and husband being away (6\%) [Table 11].

Table 11: Current Status of FP method use and Reasons for discontinuation

\begin{tabular}{|l|c|}
\hline Current status of using any FP methods by respondent and her husband & Percent ( $\mathbf{n = 1 0 0 8 )}$ \\
\hline Used before and stopped now & 27.3 \\
\hline Never used & 14.6 \\
\hline Currently using & 58.1 \\
\hline Reasons of stopping use of FP method of respondent ${ }^{ \pm}$ & 44.9 \\
\hline Became pregnant & 20.7 \\
\hline Want to have a child & 15.6 \\
\hline Missed period for some other reason & 8.7 \\
\hline Experienced side effects & 7.6 \\
\hline Infrequent sex & 5.8 \\
\hline Husband away & 3.6 \\
\hline Husband opposed & 3.7 \\
\hline Other & \\
\hline $\begin{array}{l}\text { (Multiple responses } \\
\text { *Other includes: lack of access/availability, mother in law opposed, costs too much, and inconvenient to use }\end{array}$ \\
\hline
\end{tabular}

Among respondents who had never used a method (142), the most common reasons cited were wanted to have more children (64\%), already pregnant (29\%), their husbands opposed (16\%), feared side effects (12\%), missed period $(13 \%)$, did not know any method $(9 \%)$, and their mother-in-law opposed $(6 \%)$ [Table 12]. A few stated other reasons such as infrequent sex (4\%), husband being away (2\%), religious opposition (1\%), lack of access/availability of methods (1\%), and high costs (1\%). 
Table 12: Percent distribution of respondents by reasons for never use of FP methods

\begin{tabular}{|l|c|}
\hline Reasons for never using an FP method ${ }^{ \pm}$ & Percent (n=142) \\
\hline Wants to have more children & 64.1 \\
\hline Became pregnant & 28.9 \\
\hline Husband opposed & 15.5 \\
\hline Fear of side effects & 12.0 \\
\hline Missed period for some reason & 12.7 \\
\hline Knows no method & 8.5 \\
\hline Mother in law opposed & 6.3 \\
\hline Other* & 8.4 \\
\hline $\begin{array}{l}{ }^{*} \text { Multiple responses } \\
{ }^{*} \text { Other included: infrequent sex, husband away, against religion, lack of access/availability, costs too much }\end{array}$ \\
\hline
\end{tabular}

Insights from IDIs with husbands showed that most of them started using condoms a few months after their marriage. Only one respondent mentioned that he used condom before his marriage. Five out of fourteen respondents said that they never used condoms in their lives while only two were using condoms at the time of the survey. The two who were using condoms at the time of the survey noted that their decision was based on the negative side of other FP methods that can be used by their wives. One said that he had heard that the oral pill 'burns the cord and adversely affects the abdomen' while the other noted that other methods such as injectables result in infertility.

Ten out of the fourteen husbands were not using condoms at the time of the survey because their wives were on other FP methods while others did not use condoms because their wives became pregnant by this time. Other reasons mentioned for non-use of condoms were reduced sexual pleasure, felt shy to buy from open markets or pharmacies, felt shy to go to the doctor or provider to consult about the selection and suitability of condoms, not felt necessary to use, lack of understanding between husband and wife, and lack of knowledge about condoms. Three of the husbands said that they had never used any FP methods in their conjugal life. One noted that he did not use FP methods because the relationship with his wife was not so good, they did not have good understanding of FP methods, and that sometimes they did not even talk to each other.

None of the respondents (female) in the IDIs started using any kind of FP methods from the day they got married. Some respondents only started using an FP method after their first pregnancy. First-time initiation of FP method use ranged from 1-7 days after marriage, depending on the husband's choice and the information, suggestions or instructions they received from their husbands and/or senior female members of the family. Only two respondents mentioned that they used natural FP methods (one used safe period and another used withdrawal method). None of them believed that they might get pregnant on the very first day of their marriage if they did not use any FP method during sexual intercourse. Pills and condoms were most irregularly used by the respondents. Some of them mentioned that they did not know about getting pregnant if they had unprotected sex with their husbands and if they missed taking pills for 2-3 days. Some of the respondents mentioned that they could not continue taking pill due to side effects such as vomiting, nausea, and vertigo with most discontinuing use within several days to several months for these reasons.

A few respondents mentioned about switching from the pill to other FP methods (mostly injectables) because of side effects or that they forgot to take the pill which resulted in unintended pregnancies. The majority however, indicated that they did not regularly use condoms due to their husbands' unwillingness, uncomfortable feelings, negative perceptions (may become impotent), and fear. Most of the respondents believed that prolonged use of oral pills prior to first birth would lead to infertility. This was found to be one of the most common reasons of discontinuation of oral pills. As one respondent noted: 
"I think if someone continues pills for long before birth of their first child, she may develop infertility and may lose the ability to conceive in her life in the future. So it's better to continue pills after the first baby is born." (IDI, female) (Age 17 years, 0 years of education)

The use of injections became more acceptable among the respondents (especially among those who had one or more children and wanted to stop getting pregnant) just after an unintended pregnancy occurred. Respondents who used injectables had positive views about the method and highlighted several benefits.

One respondent, for instance, noted that it was better for her to use injections than pills. Pills were good but usually she forgot to take it regularly. Her husband often forgot to bring the strip from the pharmacy when she needed it. She felt that it was shameful for a young woman to go to buy oral pills from the local pharmacy. She liked injectables because she could be safe for three months and did not have to bother everyday whether to take pills or not. Also she could buy it from the local pharmacy with only 10-15 taka according to the dates mentioned in the health card.

Only one respondent mentioned that she used Norplant as a method to avoid pregnancy for 3 years. Two respondents used the copper-T (IUD) but discontinued due to bleeding and uncomfortable feelings of the hanging thread. In both cases, they had been unwilling to use the method but due to pressure from the service providers, they had it inserted. One of them took it out within 7 days of insertion and another one continued after being counseled by a physician. As one respondent noted:

"I was totally upset and dissatisfied with copper-T as my husband was complaining about the thread which caused problem during intercourse. My husband was very angry when he saw the thread was hanging outside. He was afraid and scolded me on choosing the method." (IDI, female) (Age 17 years, 0 years of education)

\subsection{Source of getting FP information}

The most commonly cited sources of information on FP method for the respondents were husbands, friends, family members, relatives, and neighbors $(57 \%)$ as well as skilled health service providers such as doctor, nurse, midwife, government health worker or NGO health worker (41\%) [Table 13]. Other sources included unskilled health service providers such as pharmacy worker or village doctor (10\%) and the media (8\%). (Table 13).

Table 13: Percent distribution of respondents by sources of information on FP methods

\begin{tabular}{|c|c|}
\hline Sources of information on FP \pm & Percent $(n=1008)$ \\
\hline Husband/ friends/ family members/ relatives/ neighbors & 56.6 \\
\hline Skilled health service providers ${ }^{+}$ & 40.5 \\
\hline Unskilled health service providers* & 9.5 \\
\hline Media@ & 8.3 \\
\hline $\begin{array}{l}{ }^{ \pm} \text {Multiple responses } \\
+ \text { + Skilled health service providers: Doctor/nurse/midwife/traditional birtl } \\
\text { *Unskilled health service providers: pharmacy worker/village doctor } \\
\text { @Media: Street Theater/Information pamphlets (leaflet/brochure/bookl }\end{array}$ & orker/NGO health worker \\
\hline
\end{tabular}

Most (91\%) of the respondents knew of a location/provider where FP methods could be obtained. Pharmacy workers were the most commonly cited source of methods $(71 \%)$ followed by NGO facilities (53\%). Public health facilities were not as widely reported as a location for obtaining FP methods (15\%) while private facilities were rarely cited as a source of FP methods (2\%) (Table 14). 
Table 14: Percent distribution of respondents by knowledge on source of FP methods

\begin{tabular}{|c|c|}
\hline Source of family planning methods \pm & Percent $(n=1008)$ \\
\hline Public health facilities ${ }^{+}$ & 14.6 \\
\hline NGO facilities ${ }^{*}$ & 53.9 \\
\hline Private facilities@ & 1.5 \\
\hline Medicine sellers & 71.0 \\
\hline \multicolumn{2}{|l|}{${ }^{ \pm}$Multiple responses were applicable } \\
\hline \multicolumn{2}{|c|}{$\begin{array}{l}\text { + Public health facilities: Medical College Hospital/Maternal and Child Welfare Centre/ Upazila Health Complex/Family Welfare Centre/ Satellite clinic/ } \\
\text { EPI outreach/ Community Clinic/ Government Hospital/FWA }\end{array}$} \\
\hline \multicolumn{2}{|c|}{ "NGO facilities: NGO static clinic/ NGO satellite clinic/ NGO field worker } \\
\hline \multicolumn{2}{|c|}{ @Private facilities: Private Hospital / clinic } \\
\hline \#Medicine sellers: Pharmacy/ Shop/ Other & \\
\hline
\end{tabular}

Findings from IDIs with respondents showed that they first heard about FP methods from husbands, neighboring 'Bhabi' (sister-in-law), mother-in-laws, and husband's brother's wife. A few mentioned that they learned about injections from health workers through doorstep service, and at static clinics and drug sellers while information on copper-T (IUDs) was mostly obtained from health workers of static clinics. By contrast, most of the husbands had heard about condoms, oral contraceptive pills and fertility regulation from their friends, typically before marriage. For Norplant, however, the major source of information was the influential men ("bhais") of the areas where they lived. Some of the husbands also learned about these methods from NGO health centres (BRAC Delivery centres, Maternity centres), health workers, pharmacies, and books. In addition, most of the husbands learned about injectables from their wives and older friends.

\subsection{Use of MR services}

During IDIs with husbands, half of them stated they did not face any barriers in accessing and effectively using FP and MR services. However, another half of the husbands mentioned several barriers including: poverty and high cost of MR services, unwillingness of people to have MR; and high cost of condoms (15 to 20 Tk. per packet) which poor people cannot afford to buy regularly. Some husbands also stated that they were too shy to buy condoms from the pharmacy particularly when there were known elders sitting inside the pharmacy. Few mentioned that quality of MR services depends on amount of money they spend on it.

Knowledge of MR services among the husbands seemed to be very limited. A few of them who had heard about MR said that one of the NGO clinics (Marie Stopes) provided the service. One husband stated that MR is also conducted in medical hospitals. Some husbands thought that MR is a painful method and women bleed profusely after the procedure. One husband perceived MR as a great $\sin$. Of those husbands whose wives had used MR, none of them accompanied their wives to go to facility or to service provider for the services. Like their husbands, the respondents also mentioned that the quality of MR services depended on financial status. The following excerpts highlight respondents' perceptions about MR and FP:

"The offspring are the gifts from Allah [God]; it would be a great sin if we conduct MR. So, in order to avoid this great sin, we should use family planning methods." (IDI, Husband) (Age 23 years, 8 years of education, business person)

"It (use of MR) is a great sin; I think there is no such sin as big as this one." (IDI, Husband) (Age 23 years, 8 years of education, business person)

IDIs with respondents showed that MR was stigmatized and that women who sought MR services were considered 'bad' by providers in NGO and other health facilities. Some of them felt that their privacy was compromised especially in the government facility or any MR service center close to their community. As a result, they opted to use facilities that were far away from their residence where they were less likely to be recognized. 
Some of the respondents went to private clinics (outside their community) because these clinics were perceived as providing better protection of their privacy. On the other hand, some respondents noted that although MR services cost less in public hospitals, transportation costs to get to these facilities are high since they tend to be located far away from their homes. In contrast, medicines for MR are available in nearby local pharmacies and NGO clinics. Some respondents mentioned that in both public and private facilities they had to pay unofficial fees to the support staff to get MR services.

One respondent who used medicines for MR reported that if MR with medication procedure failed to terminate the pregnancy then she would keep the baby and would not undergo MVA procedure. This is because the service providers would ask for extra money to provide the MVA service and no privacy will be maintained in the facility. So, the couple better thought to consult with a 'doctor' [pharmacy worker] and have medicine for MR through which she could maintain privacy and terminate pregnancy at a low price.

\section{Discussion, Limitations and Recommendations}

\section{Discussion}

This was a cross sectional study conducted in five urban slums of Dhaka city of Bangladesh to examine the prevalence and the basic underlying factors of UP among married adolescent girls in such settings. One major finding of the study is that the level of UP was high among respondents in the study. In particular, more than half of the pregnancies (53\%) among the respondents in the study were unintended. The prevalence of UP was more than twice higher among married adolescent girls in the slums than among a similar group of adolescent girls in all urban or rural areas of Bangladesh. Estimates from the 2011 BDHS, for instance, show that among births occurring in the preceding five years before the survey to married adolescent girls aged 15-19 years in urban and rural areas, $22 \%$ and $24 \%$ of the pregnancies respectively were unintended. The findings suggest that married adolescent girls in urban areas of the country require targeted interventions to reduce the high levels of UP among them.

The second major finding of the study is that UP among married adolescent girls in the slum setting was largely due to inconsistent use of a method, being unaware of available methods, fear of side effects, method failure, and pressure from relatives (mostly husbands and mothers-in-law) to have children. Other factors included lack of spousal communication, switching methods, and wrong calculation of the safe period. Moreover, those who experienced UP were less likely to be aware of FP before they got married compared to those with intended pregnancies. UP was also significantly higher among younger than older married adolescent girls as well as among those who conceived at younger than at older ages. Given that early marriage is a social and cultural norm in Bangladesh, the findings suggest the need for sensitization programs aimed at creating awareness about the importance of consistent use of FP for birth spacing among married adolescent girls in slums in the early stages of marriage as well as among community members.

The other important finding of the study is that unintended pregnancies were more likely to result in spontaneous or induced abortion compared to pregnancies that were intended at the time of conception. Insights from IDIs showed that the decision to terminate an UP was largely due to the need to space births and to avoid health risks associated with early childbearing. In addition, the decision to terminate or continue with an UP could be made by the woman, the spouse, the mother or the mother-in-law. However, the chances of a pregnancy resulting in induced abortion were high when both the husband and the wife agreed that it was unintended. By contrast, in most cases where the wife considered the pregnancy unintended while the husband wanted it, the pregnancy was continued. There were also instances when pregnancies that were unintended by both the wife and the husband were continued due to insistence of the mother or the mother-in-law. The importance that married 
adolescent girls placed on spacing births and their recognition of health risks associated with early childbearing provide an opportunity for interventions that promote consistent use of modern FP methods among this segment of the population. Consistent use of FP should in turn help them avoid unintended pregnancies that require complex decisions on whether to terminate or continue with the pregnancy.

There is a high unmet need (15\%) for FP among married adolescent girls in the slums than among a similar group in all urban areas of Bangladesh (10\%) based on the 2011 BDHS. The level of unmet need among married adolescent girls in the slums was, however, similar to that of their counterparts in rural areas of Bangladesh $(15 \%)$. Moreover, consistent with findings from the $2011 \mathrm{BDHS}$, the level of unmet need among adolescents in the study was higher for spacing $(12 \%)$ than for limiting $(3 \%)$. It is also worth noting that unmet need for FP among adolescent girls in the slums was significantly higher among those whose marriages were arranged but did not agree to it than among those who agreed to arrange marriages. The findings further show that although the majority (85\%) of the married adolescent girls in the study had used FP before, only $58 \%$ were using a method at the time of the survey. Apart from being currently pregnant and wanting to have a child, other reasons for discontinuing use of FP were fear of side effects, opposition by the husband or other family member, and infrequent sex. Cost of methods was also cited as a major barrier to non-use. The findings highlight the need for programs aimed at supporting married adolescent girls in the slums who are already using contraception to consistently use effective methods.

\section{Study Limitations}

The findings of the study should be interpreted in light of several limitations. First, although multiple attempts were made to reach potential respondents, many employed adolescents may have systematically been excluded from participation because data collection was conducted during the daytime. The findings could also be affected by recall bias given that information was based on respondents' self-reports.

\section{Recommendations}

Based on the study findings, the following are recommendations for programmatic action:

- Conduct health education about FP among married adolescent girls: Health education on family planning for married adolescent girls is needed to promote awareness and consistent use of effective contraceptives for birth spacing among this segment of the population in order to reduce the high levels of unintended pregnancy.

- Develop community sensitization: Community sensitization is important for marshalling the support of family members and community opinion leaders for FP services for married adolescent girls. This could be achieved through courtyard meetings; offering inter-personal communications; as well as developing and distributing information, education and communications (IEC) materials on adolescent sexual and reproductive health.

- Improve counseling on FP method use for married adolescent girls and their spouses: Improved counseling on FP method use for married adolescent girls and their spouses will clear some of the barriers to use such as misconceptions and fear of side effects. Improved counseling will also ensure appropriate timing and consistent use of contraception to achieve the desired birth spacing for married adolescent girls and their spouses.

- Ensure FP services are affordable for married adolescent girls and their spouses: The issue of cost as a barrier to effective FP method use by married adolescent girls and their spouses could be addressed through a standard demand-side financing (DSF) mechanism for the very poor. The DSF mechanism should make it possible for the girls to access FP services from any facility rather than specific geographic area so that migratory groups such as those who move from one slum to another also benefit. This will ensure that 
access to proposed subsidized FP services is not disrupted when they migrate. Targeting mechanisms should include clearly defined procedures for identifying the very poor.

- Targeting specific groups with FP services: Family planning programs for married adolescent girls should put in place measures to ensure the participation or support of their spouses. In addition, the programs need to target those married adolescent girls who wish to space births and who have reached their ideal family size with a view to promoting the use of long-acting or permanent methods. Newly married adolescent girls should also be targeted with FP information and services by different means (such as, giving pamphlets during their marriage registration, giving information on FP counselling areas etc.) in order to enable them avoid unintended pregnancies. 


\section{References}

1. Santelli, J., Rochat, R., Timajchy, K. H., Gilbert, B. C., Cabral, R., Hirsch, J. S., Schieve, L., and working group (2003). The Measurement and Meaning of Unintended Pregnancy. Perspectives on Sexual and Reproductive Health. 35(2): 94-101.

2. Singh, S., Sedgh, G., \& Hussain, R. (2010). Unintended Pregnancy: Worldwide Levels, Trends, and Outcomes. Studies in Family Planning, 41(4): 241-250.

3. Gipson, J., Koenig, M., \& Hindin, M. (2008). The Effects of Unintended Pregnancy on Infant, Child, and Parental Health: A Review of the Literature. Studies in Family Planning, 39(1): 18-38.

4. World Health Organization (2012). Early marriages, adolescent and young pregnancies.

5. Santhya, K. (2011). Early marriage and sexual reproductive health vulnerabilities of young women: a synthesis of recent evidence from developing countries. Current Opinion in Obstetrics \& Gynecology. 23(5): 334-339.

6. Bangladesh Demographic and Health Survey 2011. National Instuitute of Population Research and training, Dhaka, Bangladesh. January 2013.

7. National Institute of Population Research and Training. (2008). 2006 Bangladesh Urban Health Survey. Dhaka, Bangladesh and Chapel Hill, NC, USA: NIPORT, MEASURE Evaluation, ICDDR,B, and ACPR. 